\title{
DO LOWER MINIMUM WAGES FOR YOUNG WORKERS RAISE THEIR EMPLOYMENT? EVIDENCE FROM A DANISH DISCONTINUITY
}

Claus Thustrup Kreiner, Daniel Reck and Peer Ebbesen Skov*

Abstract: We estimate the impact of youth minimum wages on youth employment by exploiting a large discontinuity in Danish minimum wage rules at age 18, using monthly payroll records for the Danish population. The hourly wage jumps up by 40 percent at the discontinuity. Employment falls by 33 percent and total input of hours decreases by 45 percent, leaving the aggregate wage payment almost unchanged. We show theoretically how the discontinuity may be exploited to evaluate policy changes. The relevant elasticity for evaluating the effect on youth employment of changes in their minimum wage is in the range 0.6-1.1.

EconLit Codes: J2, J3, H2

*Kreiner: University of Copenhagen, CEBI and CEPR; Reck: London School of Economics. Skov: Auckland University of Technology and RFF. We are grateful for discussions with John Bound, Charlie Brown, Henrik Kleven, Etienne Lehmann, Alan Manning, Niels Johannesen, Emmanuel Saez, Mike Mueller-Smith, Juan Carlos Suárez Serrato, Joel Slemrod, Jeff Smith, Isaac Sorkin, Johannes Spinnewijn, Andrea Weber and two anonymous referees. Jakob Jul Elben provided excellent research assistance. We are grateful to the Danish tax administration (SKAT) for providing monthly earnings data and to the ministry of teaching and education (Ministeriet for Børn, Undervisning og Ligestilling, Styrelsen for It og Læring) for providing data identifying apprentices. We also thank the Confederation of Danish Employers for providing information about wage agreements and legal rules. Financial support from the Economic Policy Research Network (EPRN) and the Rockwool Foundation Research Unit (RFF) is gratefully acknowledged. The activities of CEBI, Center for Economic Behavior and Inequality, are financed by a grant from the Danish National Research Foundation. Contact information: ctk@econ.ku.dk, d.h.reck@lse.ac.uk, ps@aut.ac.nz. 
Minimum wages, set by law or by collective agreement, exist in $3 / 4$ of OECD countries (OECD, 2015). In the United States, minimum wage increases have been high on the policy agenda in recent years, motivated in part by many studies finding small employment effects of minimum wage hikes. Some cities (e.g. LA, Seattle) and the state of California have recently legislated a minimum wage rate of $\$ 15$, a much higher rate than the current Federal minimum of $\$ 7.25$ per hour.

As higher minimum wages become common, policy-makers are confronted with a second question: should a high minimum wage apply to everyone? In particular, should it apply to younger workers? Young workers are low-skilled and enter the labor market without work experience, which make them potentially vulnerable to high minimum wages. Many US states and cities, including California, Minnesota, South Dakota, Kansas City and Des Moines, which have recently increased their minimum wage, have debated, and at times legislated or placed on the ballot, an exception for younger workers (Kreiner, Reck and Skov, 2018). Similarly, many European countries with high minimum wages have lower minimum wages for younger workers (OECD, 2015).

The main question we seek to answer is: Holding the adult minimum wage fixed at a given level, what is the effect of a change in the minimum wage applying to young workers on their employment? Existing US evidence and most other evidence cannot answer this question as it studies changes in a global minimum wage rather than a youth-specific minimum wage. For example, the elasticity of youth employment with respect to the minimum wage of 0.075 reported by the US Congressional Budget Office is based on changes in a global minimum wage (Congressional Budget Office, 2014).

Our empirical evidence exploits a large discontinuity in Danish minimum wage rules occurring when workers reach age 18. The Danish context is ideal for our purpose. Denmark has large changes in minimum wage rates when workers turn 18 (and no change at any other ages) and a high adult minimum wage comparable to the $\$ 15$ level in place in California and 
under consideration more generally in the US. ${ }^{1}$ Furthermore, we can study the effect of the age discontinuity using high-quality monthly data on wages, employment, and hours worked for the entire Danish workforce.

Our main findings are contained in Figure 1, which shows that the age discontinuity in minimum wages has a large impact on employment around age 18. We explain the details behind the construction of the data set, measurement issues, and the source of identifying variation below. Figure 1a plots average hourly wages, imputed by dividing reported monthly wages by reported hours worked for each individual, as a function of age (measured in months), for two years before and after their 18th birthday. The average hourly wage rate jumps by DKK 46 , or about $\$ 7$, corresponding to a 40 percent change in the wage level at age 18 computed using the midpoint method. Figure 1b plots the share of individuals who are employed by monthly age. We observe a 15 percentage-point decrease in employment at age 18, which corresponds to a 33 percent decrease in the number of employed individuals. For comparison, note that the wage and employment rates develop smoothly when individuals turn 17 and 19 years old, and that it takes two years before the employment rate is back at the level it attains just before the jump downwards at age 18. Subsequent analyses reveal that the drop in employment when workers turn 18 reflects a discrete change in job loss without any discrete change in hiring (we do observe a small anticipatory slow-down in hiring as workers approach age 18).

A simple estimate of the employment elasticity (the extensive margin) with respect to the wage change is obtained by dividing the estimates of the percentage changes in employment and hourly wage. This gives an elasticity around -0.8. When looking at total hours worked (the intensive and extensive margin), we find an elasticity of -1.1, indicating that most of

\footnotetext{
${ }^{1}$ Using the current exchange rate of $6.6 \mathrm{DKK} / \mathrm{USD}$ and the OECD's comparative price level of 125 to adjust for purchasing power parity between the US and Denmark (OECD, 2016a), the minimum wage for adult workers over 18 in Denmark is comparable to a US wage rate of about $\$ 14.50$.
} 
Figure 1: Wages and Employment around Workers' 18th Birthdays

(a) Average Imputed Hourly Wage



(b) Employment Rate

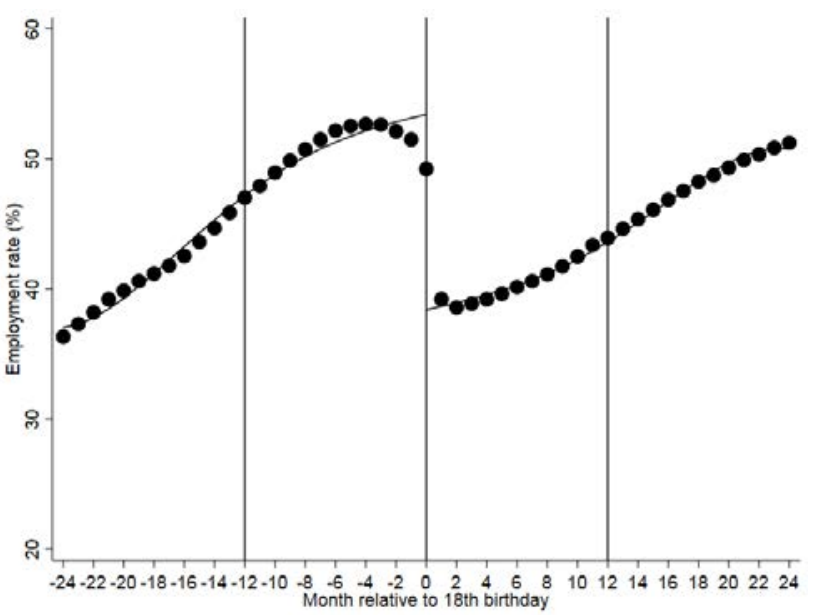

Note: This figure depicts estimates of average hourly wage rates and employment rates by age, in months, for two years before and after workers' 18th birthdays. We observe a sharp, 40 percent increase in average hourly wages when workers turn 18, which is driven by the increase in the minimum wage, and a coincident 33 percent drop in employment. We observe no changes when workers turn 17 and 19 years old. The percent change in the dependent variables and the fitted line are taken from the estimation of a regression described in Section 3. See also Table 2. 
the response occurs along the extensive margin. Recall that a unit elasticity would imply that the average wage payment of all individuals, including both employed and non-employed workers, should stay unchanged when the wage rate is raised, because its effect on the average wage payment is fully offset by a decrease in employment. Consistent with this reasoning, we find nearly no effect on average earnings. This provides alternative evidence of a total hours worked elasticity around -1, not depending on the measurement of hourly wages.

We use economic theory to motivate our empirical specification and to show that, under reasonable assumptions, the estimated employment elasticity may be used to calculate the effect on youth employment of a change in the minimum wage specifically for younger workers. First, we provide a simple model in which the elasticity we estimate using the age discontinuity is exactly the same as the elasticity needed for the desired counterfactual policy analysis. In the model, workers have exogenous, heterogeneous productivities and are hired if their productivity exceeds the minimum wage (corresponding to a horizontal demand for labor measured in effective units). In this simple setting, cross-worker effects are zero. According to this basic model, we may compute the consequences of increasing the minimum wage for young workers (those under 18) up to the higher level applying to adults by using our estimated elasticity. This calculation gives a 15 percentage point drop in youth employment, corresponding to 33 percent of initial employment.

A model with downward sloping labor demand for low-skilled work would instead suggest that there are cross-worker effects, implying that a higher youth minimum wage may increase low-skilled adult employment. Such cross-worker effects pose a potential threat to the identification strategy. However, we show that one can obtain a lower bound for the youth employment elasticity by considering the extreme case of a fixed demand for lowskilled work (implying that the employment effect from the discontinuity analysis is entirely driven by cross-worker effects). The lower bound may be computed from our estimated elasticity and the wage share of younger workers in the low-skilled labor market. We thus compute the wage share of low-skilled workers under age 18, using various definitions of the 
low-skilled workers that are perfectly substitutable for workers under age 18 . In the most extreme of these calculations, in which only workers aged 18-19 are deemed to be "low-skilled" substitutes for workers under age 18, the lower bound of the youth employment elasticity becomes 0.6 . Increasing the minimum wage for young workers up to the level of adult workers would then decrease employment by at least 11 percentage points, or 25 percent of youth employment, which is still a substantial employment effect.

We also embed our simple model in an equilibrium search framework incorporating dynamics for aging. In accordance with the empirical evidence, the model predicts that the drop in employment at age 18 reflects a discrete change in job loss, rather than a discrete change in hiring. The model also predicts spillover effects of an increase in the youth minimum wage on adult employment, but in this case the sign of the spillover effect is ambiguous. In any case, our elasticity estimate is again a good approximation of the effect on youth employment if young workers constitute a low share of total low-skilled employment."

Additional analysis demonstrates that our interpretation of the empirical results is correct and studies heterogeneity in employment effects across workers. Most importantly, we demonstrate that other policies that change when workers turn 18, such as the eligibility for Danish social welfare programs, are not driving our results. We also show that the size of the employment elasticity is only slightly larger for workers of lower ability, as proxied by school GPA in 9th grade or the income of parents. Finally, we provide suggestive evidence that job losses have persistent effects on workers. Two years after the workers' 18th birthdays, the employment rate is about 15 percentage points lower for workers loosing their job at age 18 relative to workers who kept their job.

Our paper contributes to the sizable literature on minimum wages and employment, as reviewed in Card and Krueger (2015) and Neumark and Wascher (2008). Most of this literature studies employment effects of global minimum wage hikes, while our focus is on the effects of age-specific minimum wages, where evidence is limited. Neumark and Wascher (2004) show that countries with high minimum wages also tend to have high youth unem- 
ployment, but, consistent with our results, this correlation is weaker when countries have a lower minimum wage for young workers. One new study, Kabátek (2015), analyzes an age discontinuity, in this case several small age discontinuities in Dutch minimum wages. The observed changes in wages and employment around workers' birthdays are therefore much smaller and more diffuse than in our context. The implied employment elasticity is slightly smaller than ours. Combining one large discontinuity with thorough theoretical reasoning and rich data allows us to interpret our effects in more detail and to perform credible counterfactual policy exercises.

Our results may make some readers concerned about the impact of global increases in the minimum wage on employment, a subject of intense ongoing debate. Several DD studies, most famously Card and Krueger (1994), find little to no impact of global minimum wage hikes on employment. ${ }^{2}$ Our estimates of the effect of an increase in minimum wages on employment are much larger than those typically estimated for global minimum wage hikes using DD designs. There are three factors that could explain this difference. First, estimates in existing DD studies might be attenuated by short-run frictions (Baker, Benjamin and Stanger, 1999; Sorkin, 2015; Meer and West, 2015; Aaronson, French and Sorkin, 2017), which are not relevant in our setting. Second, our study is based on a high minimum wage level compared to most previous studies. Minimum wages may not be binding at low levels and, if binding, they may increase employment due to labor market imperfections (Manning, 2003). Third, our results might be driven by cross-age substitution rather than purely a disemployment effect of the minimum wage. The first two of these factors suggest

${ }^{2}$ The empirical literature is not unanimous on this question. For instance, Jardim et al. (2017) find large disemployment effects of the recent, sizable minimum wage hike in Seattle. Recent evidence in Clemens and Wither (2016) also suggests that the 2007 to 2009 increases in the US minimum wage may have harmed employment more than indicated by previous studies, as the magnitude of the increases and the underlying macroeconomic trends made the 2007 to 2009 increases in the minimum wage more likely to be binding. 
that our results address shortcomings of the existing literature on global minimum wage hikes. However, the third is an important limitation of our study's ability to speak to this debate. Cross-age substitution would imply that we estimate higher employment elasticity in our setting than would be seen with a global minimum wage change. The extent to which this particular factor drives our large estimate determines the extent to which readers should update their beliefs about the employment effects of global minimum wage hikes. On the whole, therefore, it is difficult to imagine that our findings will make readers less concerned about employment effects of high minimum wages, but whether and to what extent they should be more concerned depends on what they believe about the mechanisms behind our results.

Our work also contributes to the theoretical literature on the effects of minimum wages. Much of the literature attempts to rationalize early DD studies finding small or even positive employment effects using models with monopsony power or other labor market imperfections (Rebitzer and Taylor, 1995; Manning, 2003; Flinn, 2006). Our findings of large, negative employment effects around age-based minimum wages align better with binding minimum wages in a competitive labor market model. The minimum wage literature often assumes that workers/jobs are homogenous with a downward sloping labor demand due to a decreasing marginal product of labor. This is in contrast to the optimal income tax literature normally assuming heterogeneous productivities (Mirrlees, 1971). Our explanations of the empirical findings are based on theory with heterogeneous productivities, similar to other recent minimum wage research (Clemens and Wither, 2016; Clemens and Strain, 2017). The fact that some individuals lose their job when they turn 18, while others keep their job, strongly suggests that heterogeneous productivity is an important aspect of the low-skilled labor market.

The rest of the paper proceeds as follows: Section 1 provides theoretical foundation for our identification and the policy implications of our results; Section 2 describes the institutional background and dataset; Section 3 presents the results; and Section 4 concludes. 


\section{Theory and Empirical Identification}

This section develops theory that informs our empirical methodology and justifies our counterfactual policy calculations. We begin with a simple model of the labor market, where we show how the age-discontinuity in minimum wages may be exploited empirically to identify the effect of a change in the youth minimum wage on youth employment. We then relax several of the more restrictive assumptions in the basic model and show that this does not greatly change the policy implications of our results.

\subsection{Basic Model and Empirical Approach}

A theory needs to explain why some individuals are still employed when they turn 18, while others lose their job, even under the realistic assumption that individuals just above and below 18 are perfect substitutes. This employment pattern is difficult to explain without introducing some kind of worker or job heterogeneity.

We start by considering a simple constant returns to scale model with worker heterogeneity similar to other recent minimum wage research (Clemens and Wither, 2016; Clemens and Strain, 2017). We broaden the scope of the heterogeneity in productivity in Section 2.3, allowing for match-specific heterogeneity for a worker-firm pair and embedding the simple model in an equilibrium search framework. Productivity of individual $i$ at age $a$ is given by $x_{i, a}=\omega_{i}+\alpha(a)$, where $\omega_{i}$ is an individual fixed effect, and $\alpha(a)$ is a function capturing changes in productivity over the life cycle. The individual productivity components $\omega_{i}$ are distributed according to a cumulative density function $F(\omega)$ on the domain $[0, \infty)$. We assume all workers have the same disutility of work and, for simplicity, we normalize their reservation wage to zero.

The minimum wage as a function of age is denoted by $\bar{w}_{a}$ and implies that only individuals with $x_{i, a} \geq \bar{w}_{a}$ are employed (denoted $e_{i, a}=1$ ). Apart from this employment condition, we make no assumptions about the determinants of the actual wage rate workers receive; employers could compete for workers so that workers would be paid their productivity, or 
firms could pay all workers the minimum wage and extract all the surplus above this level. ${ }^{3}$

The employment rate $e_{a}$ and the probability of employment of a randomly selected individual of age $a$ equals

$$
e_{a}=\operatorname{Pr}\left(e_{i, a}=1\right)=1-F\left(\bar{\omega}_{a}\right), \bar{\omega}_{a}=\bar{w}_{a}-\alpha(a)
$$

Assuming that $F(\cdot)$ is approximately linear in the relevant range of the minimum wage, the employment propensity $\operatorname{Pr}\left(e_{i, a}=1\right)$ may be approximated by a linear probability model. In this case, we may estimate

$$
\operatorname{Pr}\left(e_{i, a}=1\right)=\eta \bar{w}_{a}+\tilde{\alpha}(a)
$$

where $\tilde{\alpha}(a)$ is a simple transformation of $\alpha(a)$ in eq. (1), and $\eta=F^{\prime}(\cdot)$ is the parameter of interest for measuring the effect on youth employment of changing their minimum wage. If the minimum wage is raised by $\Delta \bar{w}$ for the youth (individuals with $a$ below some threshold $\hat{a})$, then their employment rates change by $\Delta e_{a}=\eta \cdot \Delta \bar{w}$. The $\eta$ parameter is identified empirically by the discrete jump in the minimum wage where an individual becomes an adult at age $\hat{a}$, under the assumption that productivity develops smoothly around $\hat{a}$, i.e. the life cycle relationship $\tilde{\alpha}(a)$ is continuous at $\hat{a}$. We can convert this estimate into an elasticity of employment with respect to the minimum wage by using the midpoint method (to account

\footnotetext{
${ }^{3}$ The notion that firms could extract some surplus is perhaps more intuitive when we consider the case where heterogeneity is match- or employer-specific. In subsection 2.3, we embed the basic model into a standard equilibrium search framework with match specific heterogeneity and where firms have all the bargaining power. In this case, firms only pay a worker the minimum wage because the surplus is match-specific rather than related to particular workers. For further discussion of the role of bargaining power in the effects of minimum wages, see Clemens and Wither (2016).
} 
for the large discrete changes in wages and employment).

We may also estimate the effects on average input of hours and average income by using these variables on the left-hand side of the above regression equation in place of employment. Since minimum wage rules vary somewhat in practice depending on a number of characteristics (regular work versus overtime work, type of work etc.), as we will describe more carefully in Section 3, we pursue two different strategies to measure the employment effect. One strategy is simply to estimate specification (2) and use information about statutory minimum wages for regular work in the collective agreements. Another strategy is to estimate the employment equation

$$
\operatorname{Pr}\left(e_{i, a}=1\right)=\psi_{e} 1\{a \geq \hat{a}\}+\tilde{\alpha}(a),
$$

where $1\{\cdot\}$ is an indicator function, so that $\psi_{e}$ measures the discrete change in employment at the time when individuals become adults. By estimating a similar equation for the imputed hourly wage rates of those working and combining the estimates for these discrete changes in employment $\psi_{e}$ and wages $\psi_{w}$ at $\hat{a}$, we may compute the wage-employment relationship as $\eta=\psi_{e} / \psi_{w}$, and a corresponding employment elasticity $\varepsilon$.

Note that the employment effect in the first case is measured relative to a change in statutory minimum wages, while the second strategy estimates the change in employment relative to a change in actual wages. The two methods should give the same result if the minimum wage is binding for all workers. If this is not the case then we should find that using actual hourly wages yields a larger elasticity. Note also that in principle, one could estimate this model using data from a single cohort or a single time period. With panel data, one can use data from several cohorts and multiple time periods, and also ensure that time-specific shocks or cohort-specific confounds do not bias the estimate of the elasticity in question. Allowing for such time and cohort fixed effects is a trivial extension to the model above. 
The remaining parts of this section will relax and extend the ideas of this relatively simple model to ensure that our interpretation of the empirical results is appropriately nuanced.

\subsection{Worker Substitutability and Cross-Worker Effects}

In the above analysis, the productivity of each worker is independent of other workers-as often assumed in theoretical and empirical studies of tax-transfer policy and its impact on the labor market (e.g. Mirrlees, 1971; Feldstein, 1999; Saez, 2010)-because of a horizontal demand for labor inputs (in effective units) and perfect substitutability of labor.

The perfect substitutability assumption is reasonable when looking at age groups close to the threshold $\hat{a}$. On the other hand, a 16 year old individual may not perfectly substitute for an 18 year old. In that case, a policy that, say, raises the minimum wage for all young individuals under the age of 18 , and thereby lowering their employment rate, will also reduce the productivity of 18 year olds, and thereby decrease their employment too. As a consequence, the true effect on youth employment of changing their minimum wage would be larger than suggested by our estimates because the empirical method measures youth employment relative to that of 18 year olds. As our main finding is that the effect is sizably larger than one would naively conclude from studies of global minimum wage changes, we are not overly concerned with issues that would cause the effect of a lower youth minimum wage to be even larger than our estimates suggest.

Next, we consider the case of a downward sloping labor demand curve for low-skilled workers (including all young workers), but where workers are still perfect substitutes. For simplicity, we disregard life-cycle effects on productivity, and assume that the value of output generated by low-skilled labor is given by

$$
y=f(x), x \equiv \int_{0}^{1} \int_{i(a)}^{1} \omega(i) d i d a
$$

where $x$ is total labor input measured in efficiency units, $a$ is the age of an individual, $\omega(i)$ is the productivity/ability level of individual $i$ where individuals are indexed accord- 
ing to productivity, $i(a)$ denotes the marginal individual who is employed for age $a$, and $f(\cdot)$ is an increasing, concave function. In this setting, firms will hire person $i$ of age $a$ if $\bar{w}(a) \leq f^{\prime}(x) \omega(i)$, where $\bar{w}(a)$ is the age-specific minimum wage and $f^{\prime}(x) \omega(i)$ is the marginal productivity of the individual. In line with the empirical analysis, we focus on the case of a given minimum wage rate for the young, $\bar{w}(a)=\bar{w}_{1}$ for $a \leq \hat{a}$, and a given minimum wage for adults, $\bar{w}(a)=\bar{w}_{2}$ for $a>\hat{a}$. This implies that the lowest productivity level of an employed person within age group $a$, depending on whether $a \leq \hat{a}$ or $a>\hat{a}$, is characterized by

$$
\begin{aligned}
& w_{1}=f^{\prime}\left(x^{*}\right) \omega_{1}, \text { for } a \leq \hat{a}, \\
& w_{2}=f^{\prime}\left(x^{*}\right) \omega_{2}, \text { for } a>\hat{a},
\end{aligned}
$$

where $x^{*}$ is the value of $x$ in equilibrium and $\omega_{j} \equiv \omega\left(i_{j}\right)$ when $i_{j}$ is the marginally hired person. The number of employed young individuals and adult individuals then become $\left(1-i_{1}\right) \hat{a}$ and $\left(1-i_{2}\right)(1-\hat{a})$, respectively, and their corresponding employment rates are $e_{1}=1-i_{1}$ and $e_{2}=1-i_{2}$. If $f^{\prime}(\cdot)$ is constant then this model is equivalent to the basic model above and there are no cross-worker effects. However, if $f(\cdot)$ is strictly concave, then it implies that marginal productivity is decreasing. In this case, an increase in the youth minimum wage $w_{1}$ reduces their employment $\left(e_{1}\right)$, but increases the employment of adults $\left(e_{2}\right)$, including individuals who are 18 years old. As a consequence, our regression discontinuity approach may overestimate the effect on youth employment of a change in the minimum wage. However, in Appendix A.1 we show that the true labor elasticity $\tilde{\varepsilon}$ for the effect of an increase in $w_{1}$ on $e_{1}$ is related to the estimated elasticity $\varepsilon$ from RD according to

$$
\tilde{\varepsilon} \equiv \frac{d e_{1} / e_{1}}{d w_{1} / w_{1}}=\frac{1+\epsilon \frac{(1-\hat{a}) \omega_{2}}{x^{*}}}{1+\epsilon \frac{(1-\hat{a}) \omega_{2}+\hat{\alpha} \omega_{1}}{x^{*}}} \varepsilon
$$

where $\epsilon=-f^{\prime \prime}\left(x^{*}\right) x^{*} / f^{\prime}\left(x^{*}\right)$ denotes the percentage reduction in the marginal product of each individual if aggregate employment in effective units increases by one percent. If $\epsilon=0$, 
labor demand is horizontal and $\tilde{\varepsilon}=\varepsilon$ without any bias, as in the previous section. The potential bias is largest when overall labor demand is vertical - the discontinuity effect is entirely driven by cross-worker substitution-so $\epsilon \rightarrow \infty$, in which case we have

$$
\tilde{\varepsilon}=(1-\delta) \varepsilon,
$$

where $\delta \equiv \hat{a} w_{1} /\left[\hat{a} w_{1}+(1-\hat{a}) w_{2}\right]$ is the wage share of young workers out of the aggregate wage bill of low-skilled workers. This expression implies that the maximum bias corresponds to $\delta$ percent of the elasticity estimate, and if the wage share is small then the bias will be small. When describing the empirical results in Section 3, we use this insight to obtain a lower bound of the elasticity when accounting for cross-worker effects.

\subsection{Dynamics and Search Frictions}

The above theory is silent about labor market dynamics, for example about the effect of the minimum wage on job separation and job finding rates, and also about the dynamics of workers aging. In Appendix A.2, we embed the basic model into a standard equilibrium search framework with firm-worker heterogeneity along the lines of Pissarides (2000, Ch. 6). In this setting, workers/firms are ex ante homogenous, but the productivity of a job-worker pair is drawn from a known distribution after the worker and firm meet.

We assume that firms have all the bargaining power so that minimum wages are binding, which is realistic for our setting. We compress the life-cycle dynamics into two states (young, adult) where the share of young individuals in the population is determined by a parameter $\delta .{ }^{4}$ Firms open vacancies for young and adult workers, respectively, and in the competitive equilibrium the expected benefits of a vacancy equals the expected costs. Open vacancies and workers without a job meet according to a constant returns to scale matching function,

\footnotetext{
${ }^{4}$ Note that this parameter is similar but not identical to the wage bill share in Section 2.2 , which was also denoted $\delta$. Here, $\delta$ is the fraction of workers in the given labor market that are young.
} 
but the worker is only hired if the match-specific productivity is above the minimum wage. In addition, a firm may decide to fire a worker that becomes an adult, and thereby becomes eligible for a higher minimum wage.

In this setting, we obtain the following results. First, if the adult minimum wage is higher than the youth minimum wage then firms will fire a share of the young employed workers at the time they become adults. Thus, empirically we should see a spike in the job separation rate for individuals moving into adulthood (but not in the job finding rate).

Second, a higher youth minimum wage reduces youth employment. The effect on adult employment is ambiguous. Intuitively, a higher youth minimum wage reduces youth employment and thereby reduces the flow into adult employment. On the other hand, an employed young worker will on average have a higher productivity and therefore, a higher chance of staying employed when becoming adult. This ambiguous cross-worker effect of the youth minimum wage on adult employment implies that our empirical measurement of the effect on youth employment may be positively or negatively biased. However, similar to the case of a decreasing labor demand, we find that the bias is small if the share of young workers, $\delta$, is small.

\subsection{Labor Supply Effects and Imperfect Competition}

We have, so far, considered a fixed labor supply and a competitive labor market. In such a setting, labor demand channels alone determine employment effects of binding minimum wage hikes. The literature often relaxes these assumptions to rationalize positive employment effects of minimum wage hikes. We discuss the relationship between our results and these theories here.

In Appendix A.3, we modify the basic model to allow for the possibility that a higher minimum wage could induce workers to enter the labor force, which may also change with the age of the individuals. With this modification, the employment effect we estimate consists of labor supply and demand effects. For the labor supply effect, a higher minimum wage attracts older workers into the labor force and boosts adult employment. For the labor 
demand effect, as before, young workers with productivity above the old minimum wage and below the new one are no longer employed when they turn 18. These two effects are opposite in sign, so the overall employment effect of this policy change is ambiguous. It is ex ante possible that a higher minimum wage would attract so many workers into the work force that the labor supply effect would dominate in $\eta$ and employment would increase as workers turn 18. Observing instead that employment falls suggests that the labor demand effect is dominant.

Finally, we consider the possibility of imperfect competition. As is well-known, imperfect competition may lead to a positive relationship between minimum wage levels and employment (Manning, 2003). Firms may exploit monopsony power in the labor market to keep wages below the market clearing wage, implying that the introduction of a minimum wage between the monopsony wage level and the market clearing level raises employment. To see how the mechanisms in this type of theory would work with an age-dependency in the minimum wage, consider the case where labor demand is horizontal, all individuals have the same productivity level, but their reservation wages differ, thereby giving rise to the same increasing labor supply curve within each age group. Monopsony power implies that employment is below the market clearing level, and is identical for all age groups. In this case, the introduction of binding minimum wages (below the market clearing level) with a higher level for adults implies that employment should increase when individuals move into adulthood. Like the possibility of a labor supply effect that increases employment considered above, this effect is in contrast to our empirical evidence. Hence, such mechanisms may be at play, but if so they are dominated by the other effects pulling towards a negative relationship between the minimum wage level and employment.

\section{Institutional Background and Data}

\subsection{Minimum Wages and Labor Market in Denmark}

In Denmark, and many other countries, minimum wages are set by collective wage agreements between trade unions and employers' organizations (OECD, 2015). This is organized by in- 
dustry sectors nationally. A wage agreement of an industry specifies minimum pay rates, but leaves all employment decisions to the employers (a "right-to-manage" bargaining system). The pay rates may vary with age, experience, qualifications, time of work etc. Collective bargaining agreements effectively cover 80-90 percent of all Danish workers. ${ }^{5}$ Crucially, the minimum wage level in all collective agreements increases sharply when individuals become adults at age 18. An exception applies to apprentices (similar to technical education in the US) where wages change according to education length. Some other countries and twelve US states also have a lower minimum wage requirement for young workers. The youth (age 15-24) unemployment rate in Denmark is 10.8 percent of youth labor force, which is close to the US level of 11.6 percent, and also near the median youth unemployment rate among OECD countries (OECD, 2016b).

Table 1, panel A describes the minimum wage levels specified in the wage agreement relevant for people working in supermarkets and grocery stores (called "Butiksoverenskomsten") where around 44 percent of the employed 16- and 17-year olds work in 2015 according to our data. For young workers the basic salary is DKK 63, while it is DKK 111 for adults. This corresponds to a difference of 55 percent. The minimum wage level is higher in evenings, in the weekend and for overtime work, but the difference between young workers and adults is approximately 55 percent for all categories. Appendix Table A.1 reports minimum wage levels for young workers and adults in other wage agreements. It reveals some variation across the wage agreements, but the variation is rather small, compared to the difference in wage levels between young workers and adults. The degree of dispersion in wage floors is not exceptional in Denmark and is, for example, not very different from the United States (Cahuc, Carcillo and Zylberberg, 2014).

Danish labor market policy is often characterized as following a "flexicurity" model (Andersen and Svarer, 2007). The labor market is flexible in that hiring and firing costs are quite low in a European context, in particular compared to Southern Europe. Denmark

\footnotetext{
${ }^{5}$ More information about the Danish system may be found at www.wageindicator.org.
} 
Table 1: Example: Wage Rates in Supermarkets and Grocery Stores

\begin{tabular}{lccc}
\hline \hline \multicolumn{3}{c}{ Panel A. Collective agreement } \\
\hline Young & Adult & Difference \\
Basic salary: & 63 & 111 & $55 \%$ \\
Evening: & 75 & 135 & $57 \%$ \\
Overtime: & 94 & 166 & $55 \%$ \\
Saturday: & 85 & 155 & $58 \%$ \\
Sunday: & 88 & 160 & $58 \%$ \\
Panel B. Computed from data & monthly earnings $/$ hours) \\
\hline & 17 yrs & 18 yrs & Difference \\
Data, mean & 86 & 152 & $56 \%$ \\
Data, median & 85 & 151 & $56 \%$ \\
\hline \hline
\end{tabular}

Note: This table reports the hourly wages (DKK) for workers above and below age 18 in the supermarkets and grocery stores according to their collective bargaining agreement (labelled Butiksoverenskomsten) in 2015 and according to our imputed wages using 2015 data (ES codes 4711,4719$)$. We observe that the percent changes in minimum wages in the collective bargaining agreement are very similar to the percent changes in the mean and median wage rates in our data. Percent differences are calculated using the midpoint method. 
complements this flexibility with generous social security policies, but this component of the flexicurity model is not so important in our context because the young workers in our study (age 16-19) do not qualify for UI benefits. Thus, the youth labor market in Denmark is probably not so different from the US by these parameters. It is crucial for our RD design that it is easy for firms to lay off workers (without any change in firing costs around age 18). With high firing costs, the employment response at the age-discontinuity in the wage would not be so sharp and could underestimate the employment effect of the counterfactual policy.

Young workers do not receive severance pay. Adults may receive severance pay, but this depends on seniority and typically requires at least three years of employment in a firm, making it irrelevant for our empirical analysis. It is possible to make temporary employment contracts that expire when the employee turns eighteen years old or have longer contracts, but lay off individuals when they become adults. This does not violate age discrimination laws. ${ }^{6}$ It is also legal for a firm to search explicitly for a young worker or for an adult worker.

Certain restrictions apply to the type of work done by younger individuals. Young workers are not allowed to lift more than 25 kilos, to work with certain hazardous material or to work certain large machines, and they are not allowed to handle money in certain ways. ${ }^{7}$ Additionally, only adults are allowed to drive a car, and this requires obtaining a driver's license. Our empirical analysis of the employment effects of the hike in the minimum wage when individuals become adults presumes that productivity is a continuous function of age. To the extent that productivity jumps up at age 18 because of these rules, our estimates are lower bounds of the total effect of interest. In Section 3.2, we show that our results are not confounded by certain benefits only applying to adults.

\section{$2.2 \quad$ Data}

Our main data source is an administrative register from the Danish tax agency (SKAT)

\footnotetext{
${ }^{6}$ See www.agediscrimination.info/international/Pages/Denmark.aspx.

${ }^{7}$ This is described in detail in the law document "Ungebekendtgørelsen" available at www.retsinformation.dk/Forms/R0710.aspx?id=29935.
} 
containing information about wage payments (including pension contributions) and number of hours worked at a monthly frequency for each employee in Denmark. These administrative data are reported by third parties (employers) to the Danish tax agency, which uses the information to compute annual earnings for employees' preprinted tax returns. The earnings item on the tax return is "locked," meaning that the employee can only change this item by getting the employers to change their reporting to the tax agency. All of this ensures that the data are quite accurate (Kleven et al., 2011).

The Danish tax agency is allowed to keep information in a five-year window, and we have obtained data for the period January 2012 to December 2015. The data also contains information on the age of the employee and the industry sector of the employer, as well as individual identifiers (the "CPR" numbers assigned to all Danes) enabling links to other registers. The monthly payroll data has been transferred to a centralized governmental statistical agency, Statistics Denmark, for storage and analysis, and merged with other population register data. For some of the analyses, we use information from Statistics Denmark about the job, the school performance of the individual, and parental background. We describe these variables further when we introduce them in the results section.

Our data consists of observations for each month of Jan 2012 to Dec 2015 for all individuals in Denmark who are 16-19 years old in a given month. There are 577,795 individuals and around 14 million observations. Figure A.1 in the Appendix displays the development of key statistics over time in our sample period of 48 months. Roughly half of Danish individuals age 16-19 are employed in a typical month. The figures reveal some seasonal variation, with elevated employment in the summer months and in December. Predictably, average earnings among employed individuals are also higher in the summer, especially in August. The median of hours worked is about 30 hours per month, with significant skew above the median, so that the average of monthly hours is about 60 hours in a typical month. The top decile equals the statutory level of full time work in many months, meaning that in most months, just over 10 percent of the sample works full time. Therefore, with some exceptions, 
most of these individuals work part time, often to supplement their income while pursuing an education. We also observe seasonality in hours worked that is qualitatively similar to what we observe for employment and monthly earnings. The hourly wage rate is imputed by dividing earnings by hours worked. Hourly wages are also positively skewed, with a median of about DKK 90 per month and only a little seasonal variation.

As mentioned above, wage agreements of apprentices do not have a jump in the hourly wage at age 18. In our main analyses, we therefore only include observations of individuals who are not registered as apprentices in a given month unless otherwise noted. We use the apprentices sample (6 percent of the observations) for a placebo analysis and also show that the main elasticity estimate is almost unchanged when using the full sample including apprentices (reflecting that it reduces the changes in both average employment and hourly wage at age 18).

In panel B of Table 1, we show the mean and median hourly wage rate for 17 and 18 year old employees, respectively, in the supermarkets and grocery stores computed from our data. For each age group, the mean and median are almost identical and lie in the range of the collective agreement for the age group. More importantly for our analysis, the percentage difference between wage rates of 17 and 18 year olds is 56 percent, and thus basically the same as in the collective agreement displayed in panel A.

Appendix Table A.2 shows imputed average hourly wages for 17- and 18-year olds in various sectors. Variation in average wage rates between sectors could be driven by differences in minimum wages in collective bargaining agreements, by differences in the composition of hours between conventional, weekend, and overtime hours, or by differences in the frequency with which the minimum wage is binding. In any case, we observe that the variation in wages between age 17 and age 18, which is due to the change in minimum wage rules, is typically much larger than the between-sector variation in wages at a given age. We see the same pattern when we examine the variation in statutory minimum wages imposed by specific collective bargaining agreements in Appendix Table A.1. The variation across 
ages dominates variation across sectors. There is not a one-to-one mapping from the wage agreements to the sectors as defined in our data, but note that the average of the wage changes at age 18 across the agreements (48\% in Table A.1) is very close to the average across sectors observed in the data (46\% in Table A.2).

\section{Empirical Results}

This section presents the empirical results of the paper. We show that the minimum wage hike at age 18 has a strong effect on hourly wages and employment; we provide estimates of the elasticity of youth employment with respect to changes in the youth minimum wage; we analyze potential threats to the identification strategy; consistent with the predictions of the search model, we demonstrate a large spike in job loss at age 18 without any spike in hiring; we provide suggestive evidence of a significant impact of job loss beyond just one month after the 18th birthday; and we study how these employment effects vary by worker characteristics.

\subsection{Effects on Wages and Employment}

The main results of the paper are presented in Figure 1 in the Introduction, which examines workers' hourly wage and employment at each age, in months, for two years before and after the month of their 18th birthday. We observe a large jump in wages and a large drop in employment just as workers turn 18, and no discrete changes when they turn 17 or $19{ }^{8}$ We also observe a small anticipatory drop in employment in the two months before the worker turns 18, and perhaps a small amount of inertia in the month just after the worker turns 18.

To obtain a point estimate and standard error for the size of these effects, we first estimate

\footnotetext{
${ }^{8}$ Note that for the point in the figure corresponding to exactly the month of the 18th birthday, only about half of workers will have turned 18 by the time their employment status is recorded for this month. That explains why this point appears roughly in the mid-point of the drop in employment around the 18th birthday.
} 
regressions of the following form:

$$
E\left[y_{i t}\right]=\psi \cdot 1\left\{a_{i t} \geq 18\right\}+\sum_{d=0}^{D} \alpha_{d} a_{i t}^{d}+\rho \cdot 1\left\{a_{i t}=18\right\}
$$

where $y_{i t}$ is the outcome variable. The main effect of interest is $\psi$, which captures the change in $E\left[y_{i t}\right]$ when the worker turns 18 (as in eq. (3) in the theory section). The second term on the right-hand side of this specification is a polynomial in age of degree $D$. We use $D=5$ throughout the paper. The fitted polynomial and discontinuity $\psi$ are depicted in solid lines on all figures. One can observe directly from the figures that the fit of the 5th-degree polynomial is very good and nearly linear. ${ }^{9}$ The third term is a dummy variable removing the exact month the individual turns 18 from the estimation of $\psi$, as in this month, a worker is only over age 18 for a portion of the month. To obtain estimates of the percentage change from the estimated large discrete changes $\psi$, we use the midpoint method. Within our regression framework, this percent change is:

$$
\Delta=\frac{\psi}{\sum_{d=0}^{D} \alpha_{d} a_{18}^{d}+\frac{\psi}{2}}
$$

where the denominator is evaluated where age $a$ equals exactly 18 years (216 months). Later on, we shall add several components to the regression specification in eq. (9), but we shall still compute the percent change in the outcome of interest $(\Delta)$ in the same fashion.

Table 2 presents these results for a variety of alternative specifications, for the hourly wage (estimated only for employed individuals), number of employed individuals (extensive margin), total input of hours worked (extensive margin plus intensive margin), and earnings (including zero for non-employed individuals). Column 1 of the table contains our preferred

\footnotetext{
${ }^{9}$ The results do not change much when using lower order polynomials. The employment elasticity in the baseline specification in Table 2 is 0.82 . When using lower order polynomials the elasticity becomes higher with 0.97 as the maximum (linear specification).
} 


\section{Table 2 continued}

Note: This table reports estimates of the effect of the discrete change in minimum wages occurring at age 18 on average hourly wages, employment, hours worked, and earnings. For each outcome variable, we report the coefficient of interest measuring the effect at the discontinuity, (e.g. $\psi$ in Eq. 9), and the percent change in the outcome, calculated using the midpoint method (e.g. $\Delta$ in Eq. (10)). We report 95 percent confidence intervals, calculated from standard errors clustered by (monthly) birth cohort, in square brackets below these point estimates. In Panels B and C, we report the elasticity implied by the percent change in the labor input and the percent change in hourly wages from Panel A. Column (1) is our baseline specification (Eq. 9). Subsequent columns add month and birth-year cohort fixed effects to this specification; column 4 also includes dummy variables from two months before to two months after the workers' 18 th birthdays to remove these months from the estimation of the age polynomial and discontinuity; while column 5 only uses the month before the workers' 18 th birthdays and the month after to identify the effects.

estimates, using exactly the specification in eqs. (9) and (10).

We first consider the size of the increase in average wages. For reasons discussed in the previous section, we do not observe precise (minimum) hourly wage rates, so we must instead estimate this percent change. Figure 1a and Panel A of Table 2 analyze the average of the imputed hourly wage rate around workers' 18th birthdays. We observe that wages are relatively constant around 90 DKK beforehand, and then increase to about 135 DKK after the wage change. Using eq. (10) to convert this into a percent change with our preferred specification, we estimate that this 46 DKK increase constitutes a 40 percent increase in hourly wages.

Figure $1 \mathrm{~b}$ and Panel B of Table 2 analyze the change in employment when workers turn 18. In our preferred specification in the first column of Table 2, we estimate a 15 percentage point drop in employment, equivalent to a 33 percent decrease in the number of employed workers. In other words, the presence of the wage hike causes roughly one in three workers employed before 18 to lose their jobs when they turn 18. Combining the percentage change 
in hourly wages and in employment, we obtain the implied elasticity of -0.82 shown in the table.

The increase in average hourly wages depicted in Figure 1a is driven by increases in wages throughout the distribution of hourly wages. Appendix Figure A.2 depicts deciles of the hourly wage distribution by age. The distribution is quite compressed with over 70 percent of workers having an hourly wage between 60 and 100 DKK before 18, which is similar to the range of wages dictated by collective bargaining agreements accounting for the mix of conventional, weekend, and overtime work (see Table 1 and Appendix Table A.1). We observe a sharp parallel increase in all quantiles of the hourly wage distribution. This suggests that the increase in the minimum wage that occurs at age 18 affects the vast majority of workers.

Our measurement of average hourly wages around the age-18 discontinuity does not seem substantially affected by selection bias, which might arise because those fired at age 18 systematically earn an hourly wage rate below or above the average. Appendix Figure A.3 plots average imputed hourly wages for individuals employed continuously from two months before to two months after age 18. The figure is virtually identical to Figure 1a, and the discontinuity at age 18 constitutes a 40 percent increase in average hourly wages in either case.

The effect of the minimum wage hike at age 18 on total hours worked happens mostly along the extensive margin. Figure 2a and Panel $\mathrm{C}$ of Table 2 analyze average monthly hours worked, including both employed workers and non-employed workers with zero hours worked, around the 18th birthday. This gives an elasticity of -1.1 , implying that $3 / 4$ of the total hours elasticity is explained by responses along the extensive margin. With a total hours elasticity close to -1 , it is natural to expect that the average wage earnings of all individuals, including both employed and non-employed workers, should stay unchanged when the wage rate is raised, because its effect on the earnings of employed individuals is fully offset by a decrease in employment. Consistent with this reasoning, Panel D of Table 
2 reports that the percent change in earnings is close to zero. Notice that this evidence of a total hours elasticity close to -1 is derived directly from the earnings data, and therefore does not depend on the measurement of hourly wages.

The remaining columns of Table 2 replicate the main results for a variety of alternative specifications. Column (2) of the table adds month fixed effects to the regression, and Column (3) adds month and (monthly) birth cohort fixed effects. Neither of these additions have a meaningful impact on the estimates, suggesting that neither business cycle shocks nor cohort-specific shocks affect the estimates. Relatedly, in Appendix Figure A.4, we show that the evolution of employment around workers' 18th birthdays is virtually identical for all the birth cohorts in our data.

In order to more aggressively account for the anticipatory drop in employment before age 18 and slight inertia in employment just after 18, in Column (4) we add dummy variables from two months before to two months after the workers' 18 th birthday to remove these months from the estimation of the age polynomial and discontinuity. One can think of the resulting estimate as one that more deliberately includes workers who lost their jobs in the months just before or after turning 18, rather than in the exact month they turned $18 .{ }^{10}$ With this specification, the elasticities are only slightly larger. Conversely, we may abandon any attempt to account for anticipation and inertia and simply compare wages and employment one month before and one month after workers turn 18 as done in Column (5). In this case, the elasticities are slightly smaller. For example, the elasticity of employment with respect to the minimum wage becomes -0.72 . However, we can see from Figure 1 that this specification plainly misses much of the anticipation effect that decreases employment just before workers turn 18, and thus it underestimates the total employment effect of interest.

The results above are all conducted using the estimation sample excluding apprentices,

${ }^{10}$ The smoothing required by the age polynomial clearly picks of some of this effect already. This specification also ensures that anticipation and inertia are not exercising undue influence over the shape of the polynomial. 
Figure 2: Hours Worked and Earnings around Workers' 18th Birthdays

(a) Average Monthly Hours



(b) Earnings

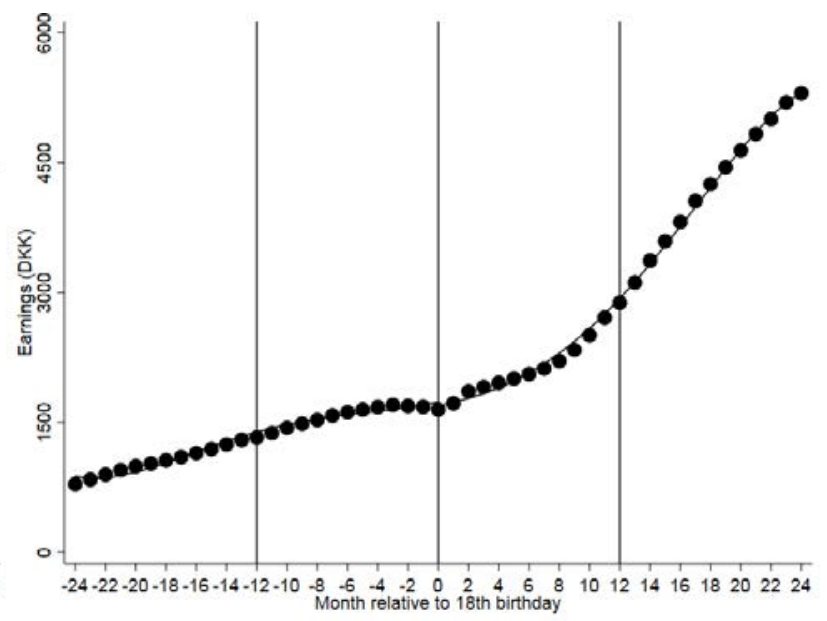

Note: This figure depicts estimates of average hours worked and earnings (including zeros) by age, in months, for two years before and after workers' 18th birthdays. We observe a sharp drop in hours worked, and very little change in earnings (see also Table 2 Panel C and D). The fitted lines depict the estimated polynomial and discontinuity at age 18 from regressions described by eq. (9). 
but our result is strongly evident in full population data as well. Appendix Figure A.5 shows that imputed hourly wage rates for apprentices do not change when individuals turn 18 . Therefore, mechanically including apprentices in the dataset should not greatly affect our imputed employment elasticity, as one can think of apprentices as representing a constant fraction of the numerator and the denominator with zero (percent) changes in employment and hourly wages at age $18 .^{11}$ However, both the percent change in employment and the percent change in hourly wages should be smaller when we include apprentices. We confirm that all this is the case in Appendix Table A.3, which shows that the estimates of the employment elasticity are almost identical whether we include apprentices or not.

Finally, we conduct additional analyses of various sectors. First Appendix Table A.4 repeats our preferred specification for supermarkets and grocery stores, which is the most important sector for youth with 44 percent of youth employment, and where we have information about the relevant collective bargaining agreement as described in Section 2.1. In this sector, both the percent change in wages and the percent change in employment are somewhat larger here than in the entire sample. The estimated percentage change in the hourly wage $(53 \%)$ is virtually identical to the percentage change in the basic salary in the bargaining agreement (55\%), strongly indicating that the minimum wage is binding. The wage increases coincide with a 62 percent drop in employment giving an elasticity estimate of -1.1 or -1.2 , depending on the method used to calculate it. Second, Appendix Figure A.7 repeats the analysis in Column (1) of Table 2 with employment in each sector and wages in each sector as the outcome variables for the top 20 sectors for youth employment (see Table A.2). We observe that changes in wages in a sector correlate strongly with changes in employment in that sector, suggestive once again of an overall employment elasticity of around -0.8 .

${ }^{11}$ This logic breaks down if individuals enter into apprenticeships just after they turn 18, perhaps due to job loss at age 18. Appendix Figure A.6 shows that this is not the case. 


\subsection{Potential Threats to Identification}

In this section, we address two important concerns with the use of the analysis in the previous section to draw inference about the effect on youth employment from a change in the youth minimum wage. One standard concern with identification in a discontinuity analysis - sorting on the running variable - is not a concern here as workers can exercise no control over the timing of their birthday. We nevertheless report in Appendix Figure A.8 the standard tests for discontinuities in observable characteristics and the density of the running variable at the month of the 18th birthday (McCrary, 2008). Here, we primarily focus on how to account for cross-worker effects in counterfactual policy analysis, and other policies that change at age 18 .

\section{Cross-Worker Effects}

The most important threat to the identification strategy is the potential for cross-worker effects as described in Section 1. An increase in the youth minimum wage may cause employers to hire more workers over age 18. This possibility would constitute a violation of the Stable Unit Treatment Value Assumption, as the policy change we are interested in would have a direct causal effect on older workers. Nevertheless, we can use the theory to bound the magnitude of the bias in the causal effect of interest - the effect on youth employment of a change in the youth minimum wage-in the presence of cross-worker effects. As shown in formula (8), the true elasticity of youth employment with respect to the youth minimum wage is bounded below by $(1-\delta) \varepsilon$, where $\varepsilon$ is our reduced form elasticity from the discontinuity and $\delta$ is the wage share of under-18 workers in the low-skilled labor market. This lower bound corresponds to the extreme case of a fixed demand for low-skilled work, so that the discontinuity in youth employment we estimated in Figure $1 \mathrm{~b}$ is entirely driven by cross-worker effects. Our estimate of the employment effect at age 18 should thus be a good approximation of the actual effect when the share of workers under age 18 in the low-skilled labor market is plausibly relatively small.

Table 3 contains information on the wage share of workers under age 18, for various 
definitions of low-skilled work. About 2.8 percent of employed individuals are under age 18, and, due to the fact that younger workers work fewer hours on average than older workers, the share of employment in hours is even smaller, at 0.8 percent. Focusing on wage shares to match our theory, we find that the overall wage share is 0.3 for young workers. The last column of Table 3 reports the lower bound for the elasticity of youth employment with respect to the youth minimum wage obtained from plugging in the given wage share as the value of $\delta$ and our baseline estimate for the wage elasticity from the discontinuity $(\epsilon=0.82)$. Using a wage share of 0.3 percent results in no meaningful change in the elasticity. However, the theory that gives the bounding result suggests that we should be using the wage share for low-skilled work that is perfectly-substitutable for work by employees under age 18. Various approaches to pin down this number lead to a higher wage share as shown in Table 3. One approach is to use a concept of low-skilled workers that includes workers similar to young workers, based on their sector (e.g. supermarkets), their hourly wage rate, or their education. These definitions lead to wage shares ranging from 1 to 7 percent, which are once again small enough that they have little effect on the implied elasticity. A more conservative method for defining low-skilled work is to suppose that only younger workers are perfectly substitutable for workers under age 18. In an extremely conservative calculation, in which we assume the only substitutes for 16- and 17-year-olds are 18- and 19-year olds, we obtain a wage share of 26.5 percent. This conservative wage share leads to a lower bound of the true elasticity of youth employment with respect to the youth minimum wage of 0.60 . With this lower bound elasticity, increasing the youth minimum wage up to the level of adults would decrease youth employment by 24 percent instead of 33 percent, which is still a sizable employment effect.

\section{Other Changes at Age 18}

The other important potential threat to our identification strategy is that other discrete changes happening when individuals turn 18 may create a jump in the employment rate. We are aware of two such changes. First, as described in section 2.1, there are a few limitations on the type of work that young workers may carry out: not lift more than 25 kilos, not work 
Table 3: The Share of Younger Workers in the Low-Skilled Labor Market

\begin{tabular}{lcc}
\hline \hline Population & Share age $16-17(\%)$ & Lower bound elasticity \\
\hline Full population & 4.0 & \\
Employment (persons) & 2.8 & \\
Employment (hours) & 0.8 & 0.82 \\
Wage income & 0.3 & 0.80 \\
Low-skilled occupations ${ }^{*}$ & 2.1 & 0.77 \\
Supermarkets & 6.5 & 0.81 \\
Hourly wage $<95$ th percentile for 18 yr olds ${ }^{* *}$ & 1.0 & 0.80 \\
Highest Education 9 th grade or lower ${ }^{* * *}$ & 2.2 & 0.77 \\
Individuals age 16-24 & 5.6 & 0.60 \\
\hline Individuals age 16-19 & 26.5 & \\
\hline \hline
\end{tabular}

Note: This table reports the wage share of workers aged 16 and 17 in selected populations, providing suggestive evidence on the share of younger workers in the low-skilled labor market, and computes the corresponding lower bound elasticity estimate using formula (9). In the baseline calculations, we use data for all Danish employees age 16-65. In the last two rows, we assume that only workers of age 18-24 and 18-19, respectively, may substitute for young workers. ${ }^{*}$ We identify low-skilled occupations using four-digit ISCO classification. We select the 10 most important occupations/job types for youth, which correspond to $\approx 83 \%$ of youth employment. ** We define low-skilled, adult workers as having a wage below the 95th percentile for 18 year olds. *** We count low-skilled workers as all workers over 18 with an education level of 9 th grade or lower, together with all 16- and 17-year-old workers. 
with certain hazardous materials and machines, and not make money transports. These rules tend to raise the productivity, and thus the employment, of 18-year-olds relative to 17-yearolds. The true effect of the wage discontinuity, adjusting for any increase in productivity from additional permitted work activities, would then be even larger than what we estimate.

Second, adults are eligible for benefits payments for certain social programs, specifically student benefits for those pursuing post-secondary education and general social assistance payments for those not in education/employment and fulfilling additional requirements. If workers started receiving either of these benefits and, as a result, stopped working, we would overestimate the effect of the minimum wage increase on employment by attributing the full drop in employment at age 18 to the minimum wage increase. Figure 3 replicates our main results in samples constructed in such a way that we can rule out that the drop in employment at age 18 is driven by either student benefits or social assistance.

Individuals are eligible for student benefits in the quarter after turning 18 years old, and when receiving student benefits they are allowed to earn DKK 7,500-11,800 per month, ${ }^{12}$ depending on the type of education, after which student benefits are phased out with the level of your earnings. Importantly, this is computed on an annual basis. In Figure 3a, we restrict our analysis to October birth cohorts. As student benefits can only be received starting in the quarter after individuals turn 18, individuals born in October can only begin receiving student benefits in January of the next year, and income earned in October-December has no bearing on the amount of student benefits, because income in these months does not count towards income in the year the student receives student benefits. The figure reveals a drop in employment exactly at age 18 that is nearly identical to what we see in the main analysis (Figure 1b), although the development is naturally somewhat noisier than the earlier results due to the smaller sample size. As explained, this drop in employment cannot be attributed to a supply effect driven by student benefit eligibility. We also observe changes in employment due to seasonal patterns (see also Figure A.1a), and very little change in

\footnotetext{
${ }^{12}$ Level in 2015 obtained from www.su.dk.
} 
employment three months after the individual becomes eligible for student benefits.

In the data, we can directly observe which individuals receive social assistance. Around 5 percent of 18 year old individuals receive social assistance. In Figure 3b, we repeat the main employment graph for individuals who never receive social assistance at any point in time in our sample period. The graph is almost identical to Figure $1 \mathrm{~b}$ and so are the key estimates of the wage change and employment effect; a 36 percent increase in imputed hourly wages and a 32 percent decline in employment at age 18.

Overall, this robustness analysis suggests that substitution between labor market earnings and either student benefits or social assistance cannot explain our main results. These findings, along with the absence of any other significant changes in policy or other incentives to work that occur when individuals turn 18 , lead us to conclude that the decline in employment we observe when workers turn 18 is driven by a decline in labor demand because of the increase in minimum wages.

\subsection{Employment Flows}

The employment effect we observe in Figure $1 \mathrm{~b}$ is driven largely by a jump in the job separation rate, as predicted by our search model in Section 1.3. Figure 4 decomposes the overall changes in employment into the flows in and out of employment around workers' 18th birthdays. For the flow in, we tabulate the fraction of workers not employed in the current month who become employed in the subsequent month. The flow out tabulates the fraction of workers employed in the current month who are no longer employed in the subsequent month. A large spike in flows out of employment occurs just after workers turn 18 as predicted by the search model. This spike drives the drop in employment observed in Figure 1b. The effect is almost entirely concentrated in a three-month period, from the month of the workers' 18th birthdays to two months later. We also observe a slight decrease in the flow into employment just before the 18th birthday, suggesting that employers are somewhat reluctant to hire workers who will turn 18 very soon. This explains the slight decrease in the rate of increase in employment depicted just before the 18th birthday in 
Figure 3: Replications of Main Employment Result for Select Sub-Samples

(a) October Birth Cohorts

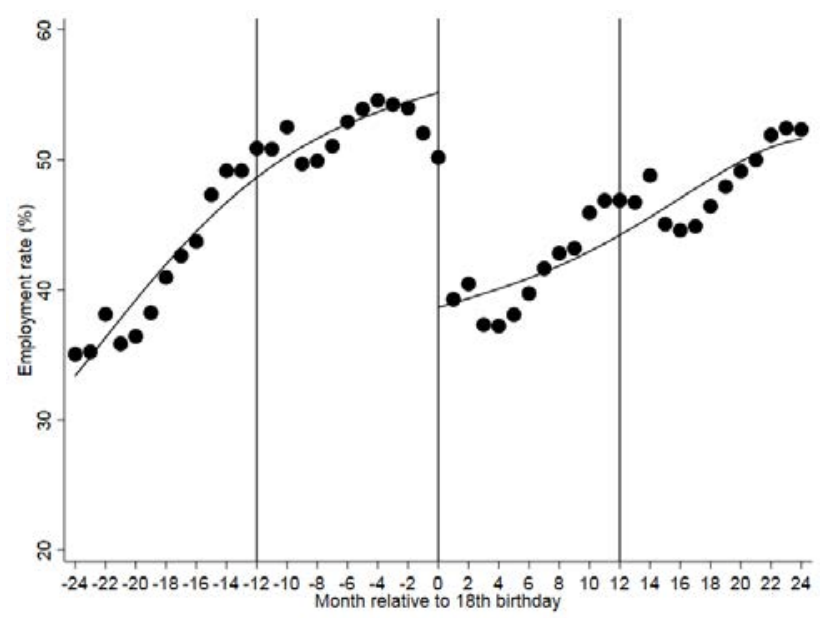

(b) Workers Never Receiving Social Assistance

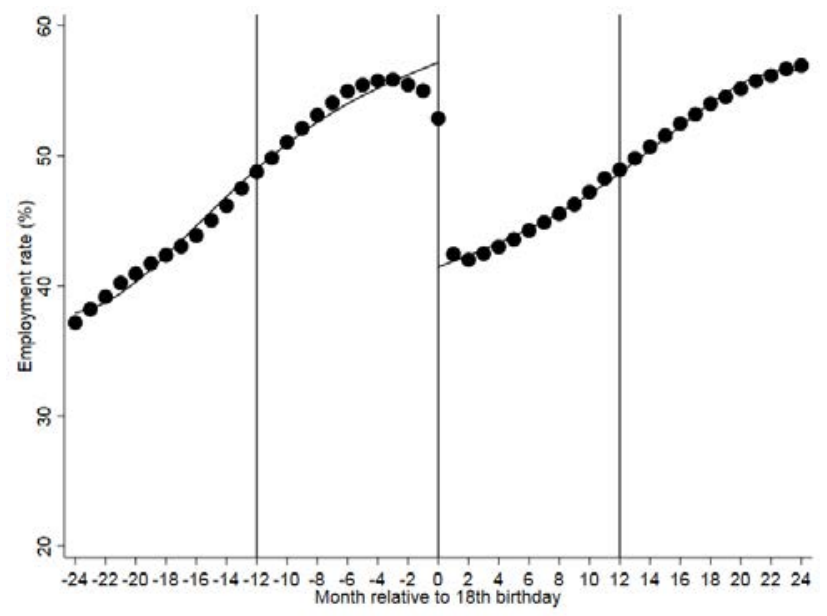

Note: This figure replicates the main result in Figure $1 \mathrm{~b}$ for select sub-samples. These replications ensure that the results are not driven by workers leaving employment because they become eligible for student benefits (which could not be received until three months after the 18th birthday for October birth cohorts), or because they start receiving social assistance. 
Figure 1b, suggesting that the anticipation effect is primarily driven by a drop in hiring. Apart from the months right after the 18th birthday, the flow into employment is slightly greater than the flow out, which reflects that as they age, workers are more likely to seek a job and/or to find a job conditional on seeking one.

\subsection{Differences across Groups of Workers}

Figure 5a reports estimates of the employment elasticity (based on imputed hourly wages) by deciles of workers' Grade Point Averages (GPA) in 9th grade of school (the last year of compulsory schooling where students are 15-16 years old). We observe that the employment elasticity is slightly decreasing in GPA, falling from roughly -0.9 to -0.7 from the bottom to the top decile of GPA. While this difference of about 0.2 in the elasticity is small relative to the overall elasticity, the direction of the change is roughly what one would hypothesize from our basic model: lower ability workers are more likely to lose their job when they turn 18 and are subject to the higher minimum wage. Nevertheless, the elasticity remains large even for students with high GPAs. In Figure 5b, we report equivalent elasticities by deciles of workers' parental income using the average income of individuals' parents from age 11 to 13. Here, we find elasticities that are only very slightly decreasing across the distribution of parental income. The similar elasticities show that a wage increase has a stronger effect on the unemployment risk of young individuals with lower ability, but the differences are relatively small. That our estimated elasticities are nearly unrelated to these broad measures of underlying ability levels is consistent with the search model in Section 1.3 where workers 
Figure 4: Employment Entry and Exit Rates around Workers' 18th Birthdays

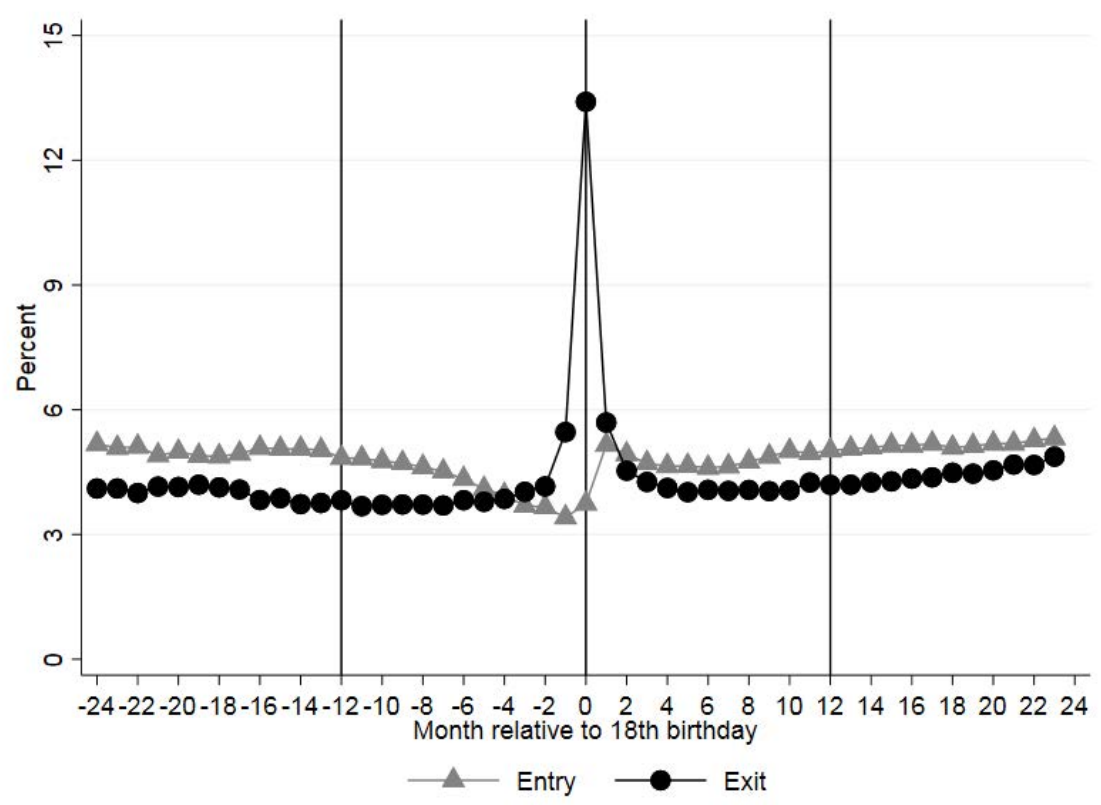

Note: This figure shows that our results are driven primarily by a spike in workers exiting employment when they turn 18, and also a slight decrease in entry into employment before workers turn 18 . We calculate the rate of entry into employment as the fraction of workers not employed in a given month who become employed in the subsequent month. The rate of exit is defined similarly. 
Figure 5: Employment Elasticity by Worker Characteristics

(a) Grade Point Average



(b) Parental Income

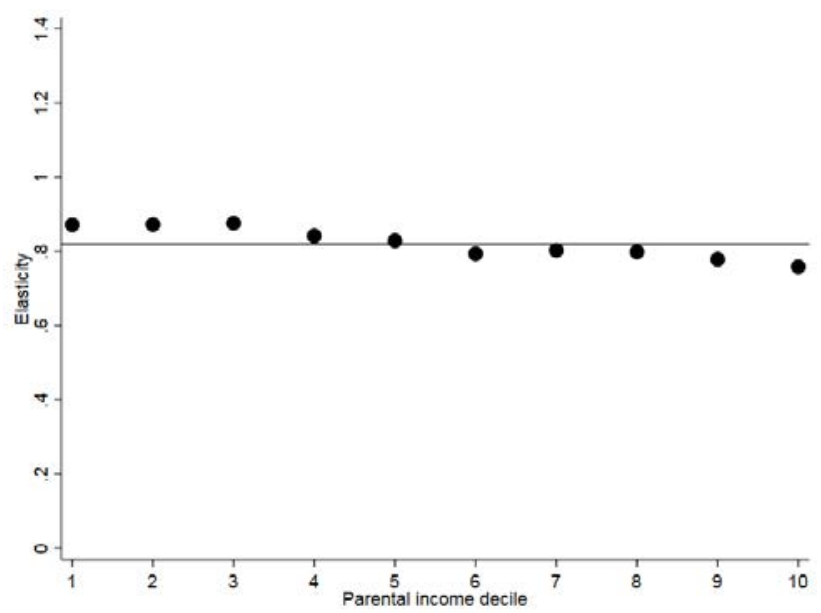

Note: This figure depicts estimated elasticities of employment with respect to hourly wages, as in Table 3, Column (1), panel B, by deciles of workers GPA and parental income. We use GPA in 9th grade, which is the last year of compulsory schooling, when workers are 15 to 16 years old. For parental income, we use the average parental income from ages 11 to 13, and construct deciles separately for each birth cohort. The elasticity in the overall population is depicted as a horizontal line in both figures. We observe that the elasticity is slightly larger for workers with lower GPA or lower parental earnings, but the magnitude of the difference is small relative to the overall elasticity. 
(and firms) are ex ante identical. ${ }^{13}$

\subsection{Consequences of Job Separations}

Finally, we present some evidence suggesting that the consequences of job loss when workers turn 18 are non-trivial. One might think from the results thus far that workers simply retime their endogenous job switches to coincide with the break in minimum wages at age 18 . That is, workers looking to change jobs might wait to do so until they turn 18, or do so earlier than they otherwise would because they turned 18. The data on job flows in Figure 4 already suggests this is unlikely: the flow into employment does not increase significantly after workers turn 18, as one would expect if workers losing their job at age 18 already had a backup plan. Evidence that job loss at 18 has effects further out beyond the month workers turn 18 further suggests that the explanation for our findings really is one of involuntary job loss due to demand-side factors in the labor market.

In Figure 6a, we look at the rate of employment after turning 18, for workers employed at age 17 years and 11 months that did and did not lose their jobs when they turned 18. These rates of employment are at 0 and 100 percent at 18 years plus one month mechanically. If job loss at age 18 were relatively inconsequential, we should expect relatively quick convergence of these employment rates. Almost 20 percent of individuals leaving employment one month after turning 18 do find another job in the next month. However, by one year after job separation at age 18, only 40 percent of separated individuals are employed, compared to just over 75 percent of individuals who did not experience a separation. Two years after turning 18, the difference in employment rates between the two groups is still more than 15

${ }^{13}$ To complement Figure 5a, Appendix Figure A.9 shows the predicted hourly wage and employment rate at age 18 by GPA and parental income for the low minimum wage and the high minimum wage. The wage rates do not depend on GPA or parental income. The employment rates are increasing in GPA, as may be expected from the theory, but the change in the employment rate is also increasing, so that the percentage change in employment and the elasticity of employment with respect to the wage are roughly constant. 
percentage points. In the months prior to turning 18, individuals experiencing a separation at age 18 were only a few percentage points less likely to be employed than individuals who were employed after age 18, suggesting that these differences are unlikely to be driven solely by unobservable worker characteristics that correlate with employment. ${ }^{14}$

Figure $6 \mathrm{~b}$ shows average earnings (including zeros for those not working) for the two groups. The development of earnings mirrors the development of employment. In particular, the job separation event creates a significant earnings gap between the two groups that also exists two years after when the individuals become twenty years old.

\section{Conclusion}

Danish minimum wages cause an increase in average wages of 40 percent when workers reach age 18. This increase in wages causes a 33 percent decrease in employment when workers turn 18, almost all of which comes from job loss. Theory suggests that we can use this effect to estimate the effect of a change in the youth minimum wage on their employment, holding adult minimum wages fixed. Applying this reasoning, we find that the relevant employment elasticity is likely in the range of 0.6 to 1.1 . This elasticity is much larger than the elasticity of youth employment with respect to minimum wages, typically estimated via difference in differences with a global minimum wage change, which we argue is not the appropriate elasticity to study the employment effects of youth-specific minimum wages on youth employment. Other explanations for the higher elasticity include that the difference in diferences estimates may be attenuated by short-run frictions, and that high Danish minimum wages are much more likely to be binding than the low minimum wages typically seen in many other countries, e.g. the US. In any event, our results suggest that adopting

${ }^{14}$ This conclusion is confirmed by Appendix Figure A.10, which shows the results from an analysis where we match the group becoming unemployed at an age of 18 years and 1 month to the employment group using propensity score matching based on employment trajectories from age 16 to 17 . The employment rates after job loss (from $t=1$ to 12 ) mirror Figure 6a, suggesting that the result is not driven by selection. 
Figure 6: Effect of Job Separations at Age 18 on Future Employment and Earnings

(a) Employment

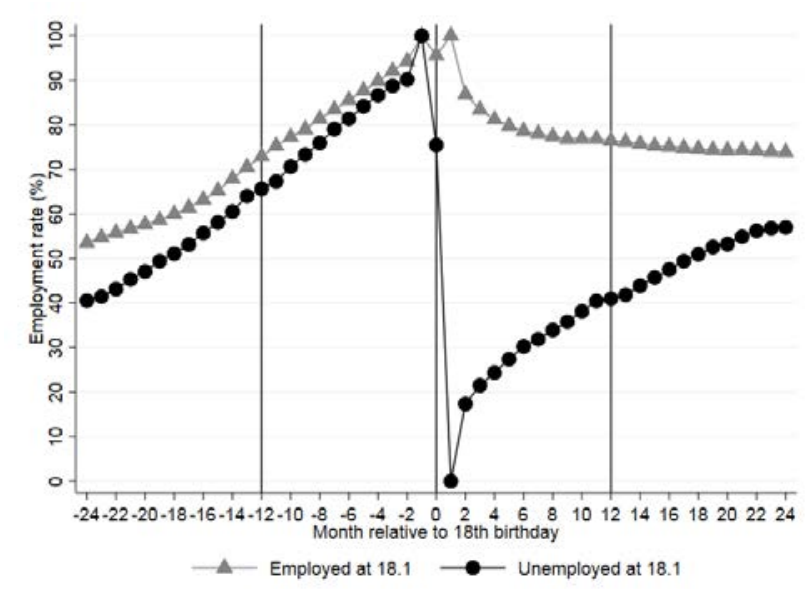

(b) Earnings

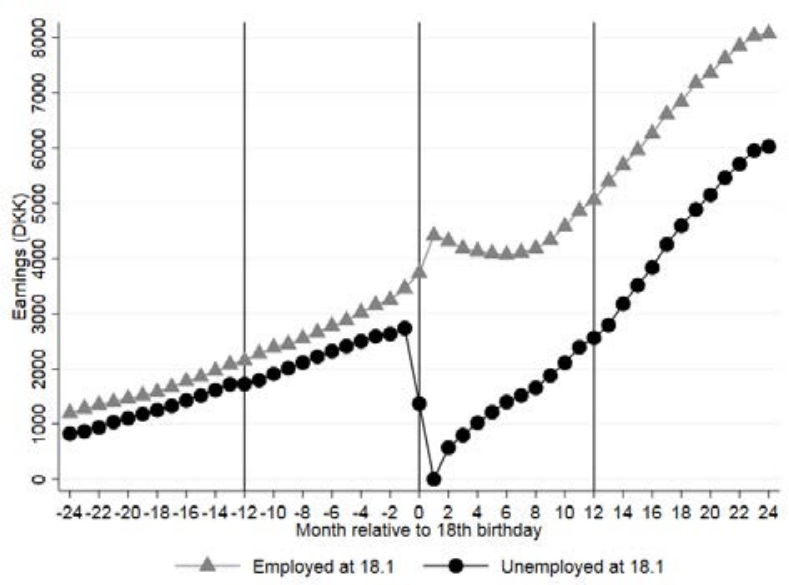

Note: The graphs depict employment (panel a) and labor income (panel b) around the 18th birthday for workers employed in the month before they turn 18. We consider only cohorts born in 1995-96 where we have observations for all months. We split the sample into workers who remain employed in the month after they turn 18, and those who are no longer employed in the month after they turn 18. We observe a large gap in future employment rates and in earnings between those who stay employed and those who leave employment, even two years after the month workers turn 18. 
a lower minimum wage for younger workers would substantially increase youth employment in US regions that adopt a high minimum wage, and it would also likely increase youth employment in European countries that already have a relatively high minimum wage.

As discussed in the Introduction, our results do not imply that studies of global minimum wage increases are necessarily underestimating the effect on youth employment. Arguably, we do identify an upper bound for the employment effects of global minimum wage increases on workers around age 18. An employer facing an increase in the minimum wage when a certain worker turns 18 essentially has all of the margins of substitution available from a global minimum wage hike - substitution for more skilled labor or capital - plus one more: substitution across worker ages. Such reasoning is based on a partial equilibrium model. However, global minimum wage hikes also have plausibly different general equilibrium effects on employment, prices etc. (MaCurdy, 2015). In any case, caution is warranted when considering the implications of our results for global minimum wage hikes. We have focused on the employment effects of youth minimum wages specifically for this reason.

Youth employment is often a focal point in policy discussions about minimum wages. The effect on youth employment is a vital input to evaluate the welfare impact of youth minimum wage changes, but it is decidedly not the only factor. For example, our discussion of crossworker effects above highlights that if employers substitute from older to younger workers when the youth minimum wage falls, employment effects on adults are also relevant. This substitution effect is difficult to identify with our data and empirical strategy. Additionally, the exact process by which jobs for youth and adults are rationed in the presence of binding minimum wages may also matter for the welfare effects of changes to the youth minimum wage (Gerritsen, 2017). Finally, increasing youth employment will alter the accumulation of experience and thereby some kinds of human capital, which could have important effects on workers' labor market outcomes beyond the contemporaneous effect on employment. Evaluating the impact of youth minimum wages on these factors is a topic for future research. 


\section{References}

Aaronson, Daniel, Eric French, and Isaac Sorkin. 2017. "Industry Dynamics and the Minimum Wage: A Putty-Clay Approach." International Economic Review, 59(1): 51-84.

Andersen, Torben M., and Michael Svarer. 2007. "Flexicurity - Labour Market Performance in Denmark." CESifo Economic Studies, 53(3): 389-429.

Baker, Michael, Dwayne Benjamin, and Shuchita Stanger. 1999. "The Highs and Lows of the Minimum Wage Effect: A Time-Series Cross-Section Study of the Canadian Law." Journal of Labor Economics, 17(2): 318-350.

Cahuc, Pierre, Stéphane Carcillo, and André Zylberberg. 2014. Labor Economics. MIT Press.

Card, David, and Alan B. Krueger. 1994. "Minimum Wages and Employment: A Case Study of the Fast-Food Industry in New Jersey and Pennsylvania." American Economic Review, 84(4): 772-793.

Card, David, and Alan B. Krueger. 2015. Myth and Measurement: The New Economics of the Minimum Wage. Princeton University Press.

Clemens, Jeffrey, and Michael R. Strain. 2017. "Estimating the Employment Effects of Recent Minimum Wage Changes: Early Evidence, an Interpretative Framework, and a Pre-Commitment to Future Analysis." NBER Working Paper 23084.

Clemens, Jeffrey, and Michael Wither. 2016. "The Minimum Wage and the Great Recession: Evidence of Effects on the Employment and Income Trajectories of Low-Skilled Workers." NBER Working Paper 20727.

Congressional Budget Office, Congress of the United States. 2014. "The Effects of a Minimum-Wage Increase on Employment and Family Income." Publication 44995. 
Feldstein, Martin. 1999. "Tax Avoidance and the Deadweight Loss of the Income Tax." Review of Economics and Statistics, 81(4): 674-680.

Flinn, Christopher J. 2006. "Minimum Wage Effects on Labor Market Outcomes Under Search, Matching, and Endogenous Contact Rates." Econometrica, 74(4): 1013-1062.

Gerritsen, Aart. 2017. "Equity and Efficiency in Rationed Labor Markets." Journal of Public Economics, 153: 56-68.

Jardim, Ekaterina, Mark C. Long, Robert Plotnick, Emma van Inwegen, Jacob Vigdor, and Hilary Wething. 2017. "Minimum Wage Increase, Wages, and Low-Wage Employment: Evidence from Seattle." NBER Working Paper 23532.

Kabátek, Jan. 2015. "Happy Birthday, You're Fired! The Effects of an Age-Dependent Minimum Wage on Youth Employment Flows in the Netherlands." Working Paper.

Kleven, Henrik, Martin Knudsen, Claus Thustrup Kreiner, Søren Pedersen, and Emmanuel Saez. 2011. "Unwilling or Unable to Cheat? Evidence from a Tax Audit Experiment in Denmark." Econometrica, 79(3): 651-692.

Kreiner, Claus T., Daniel Reck, and Peer Ebbesen Skov. 2018. "Do Lower Minimum Wages for Young Workers Raise their Employment? Evidence from a Danish Discontinuity." CEPR Discussion Paper 12539.

MaCurdy, Thomas. 2015. "How Effective is the Minimum Wage at Supporting the Poor?" Journal of Political Economy, 123(2): 497-545.

Manning, Alan. 2003. Monopsony in Motion: Imperfect Competition in Labor Markets. Princeton University Press.

McCrary, Justin. 2008. "Manipulation of the Running Variable in the Regression Discontinuity Design: A Density Test." Journal of Econometrics, 142(2): 698-714. 
Meer, Jonathan, and Jeremy West. 2015. "Effects of the Minimum Wage on Employment Dynamics." Journal of Human Resources, 52(2): 500-522.

Mirrlees, James A. 1971. "An Exploration in the Theory of Optimum Income Taxation." The Review of Economic Studies, 38(2): 175-208.

Neumark, David, and William Wascher. 2004. "Minimum Wages, Labor Market Institutions, and Youth Employment: a Cross-National Analysis." Industrial \& Labor Relations Review, 57(2): 223-248.

Neumark, David, and William Wascher. 2008. Minimum Wages. MIT Press.

OECD. 2015. "Focus on Minimum Wages after the Crisis: Making Them Pay." OECD Directorate for Employment, Labour and Social Affairs Report.

OECD. 2016a. "Comparative Price Levels." OECD Statistics.

OECD. 2016b. "Youth Unemployment Rate (indicator)." OECD Statistics.

Pissarides, Christopher A. 2000. Equilibrium Unemployment Theory. MIT press.

Rebitzer, James B., and Lowell J. Taylor. 1995. "The Consequences of Minimum Wage Laws Some New Theoretical Ideas." Journal of Public Economics, 56(2): 245-255.

Saez, Emmanuel. 2010. "Do Taxpayers Bunch at Kink Points?" American Economic Journal: Economic Policy, 2(3): 180-212.

Sorkin, Isaac. 2015. "Are There Long-Run Effects of the Minimum Wage?" Review of Economic Dynamics, 18(2): 306-333. 